\title{
THE SPECIES-SPECIFIC REGENERATIVE EFFECTS OF NOTOCHORDAL CELL-CONDITIONED MEDIUM ON CHONDROCYTE-LIKE CELLS DERIVED FROM DEGENERATED HUMAN INTERVERTEBRAL DISCS
}

\author{
F.C. Bach ${ }^{1}$, S.A.H. de $\operatorname{Vries}^{2}$, A. Krouwels ${ }^{3}$, L.B. Creemers ${ }^{3}$, K. Ito ${ }^{2,3}$, B.P. Meij ${ }^{1}$ and M.A. Tryfonidou ${ }^{1, *}$ \\ ${ }^{1}$ Department of Clinical Sciences of Companion Animals, Faculty of Veterinary Medicine, Utrecht University, \\ Utrecht, the Netherlands \\ ${ }^{2}$ Orthopaedic Biomechanics, Department of Biomedical Engineering, Eindhoven University of Technology, \\ Eindhoven, the Netherlands \\ ${ }^{3}$ Department of Orthopaedics, University Medical Centre Utrecht, Utrecht, the Netherlands
}

\begin{abstract}
During intervertebral disc (IVD) maturation, the main cell type shifts from notochordal cells (NCs) to chondrocytelike cells (CLCs). NCs secrete factors with regenerative potential, making them an interesting focus for regenerative treatments. During initial development, these strategies preferably employ non-human donors due to easy availability of their NC-rich nucleus pulposus (NP) tissue. To increase the success of translating these strategies for clinical application, this study aimed to delineate whether NC-secreted factors of different species have a regenerative effect on human CLCs. Human, canine and porcine NC-rich NP tissue and NC-conditioned medium (NCCM) were analysed biochemically and histologically. Human CLC micro-aggregates from degenerated IVDs were cultured in human, canine or porcine NCCM. Collagen, glycosaminoglycan (GAG) and DNA content was determined and histology was performed. Canine and porcine NPs were richer in NCs than human NPs. Human NPs contained the highest collagen content, whereas the DNA and GAG content of canine NPs was significantly higher than that of human or porcine NPs. NCCM from all species significantly increased the DNA and GAG content of the human CLC micro-aggregates. Porcine and canine NCCM were significantly more potent than human NCCM in inducing GAG deposition, whereas only human NCCM induced collagen type II production. Secreted factors from human, canine and porcine NC-rich NPs exerted regenerative effects on human CLCs, indicating a cross-species effect. Bioactive compound(s) are present in NCCM of different species that may reverse human IVD degeneration, supporting further research into strategies based on NC-technology employing canine or porcine models for their translation into humans.
\end{abstract}

Keywords: intervertebral disc degeneration, nucleus pulposus, notochordal cells, notochordal cell-conditioned medium, canine, porcine, human, regenerative medicine, tissue repair.

*Address for correspondence:

Marianna A. Tryfonidou

Department of Clinical Sciences of Companion Animals Faculty of Veterinary Medicine, Utrecht University Yalelaan 108, 3584 CM Utrecht, The Netherlands Telephone number: +31 302534558

E-mail: m.a.tryfonidou@uu.nl

\section{Introduction}

Low back pain affects nearly $75 \%$ of the human population at some stage in their lives (Hohaus et al., 2008). Consequently, low back pain is a serious socioeconomic burden: in the US, the total cost exceed \$ 100 billion per year (Katz, 2006). Degeneration of the intervertebral disc (IVD) has been associated with low back pain. The IVD arises from the embryonic notochord and mesenchyme and is situated between the vertebrae, where it transmits loads and allows stable multi-directional spinal mobility (Potier et al., 2014; Risbud et al., 2010). The healthy IVD consists of the annulus fibrosus (AF) and nucleus pulposus (NP). Degeneration of the IVD is a complex, multifactorial process that is characterised by changes in the cell phenotype and composition of the extracellular matrix. During IVD degeneration, the glycosaminoglycan (GAG, a proteoglycan side chain) and water content decreases in the NP, changing the biomechanical environment of the IVD cells. Because of the changed IVD matrix, diffusion of nutrients becomes impaired, which further deteriorates the health of the IVD cells and healthy matrix synthesis. Since the avascular IVD exhibits inadequate matrix repair, a vicious circle develops in which the IVD weakens and experiences increased vulnerability to damage by physiologic loading (Bergknut et al., 2013; Colombini et al., 2008).

Current medical, physiotherapeutic and surgical treatments for IVD disease aim at reducing neurological deficits and pain, rather than IVD repair. For this reason, regenerative strategies like gene-, growth factor- or cellbased therapies, that try to repair the degenerated IVD biologically, have gained increasing interest (Bach et al., 2014; Gilbert et al., 2013). They either aim at increasing the cell numbers by cell transplantation and/or by stimulating proliferation of the resident cells or matrix anabolism. Thus far, several growth factors and peptides (e.g. bone morphogenetic protein, Link N) have been shown to promote cell proliferation and/or matrix formation in vitro and/or in vivo in animal models with experimentally induced IVD degeneration (Chujo et al., 2006; Huang et al., 2007; Kwon et al., 2013; Masuda et al., 2006; Mwale et al., 2011). In addition, cell-based treatments using mesenchymal stromal cells (MSCs), articular chondrocytes and chondrocyte-like cells (CLCs) derived from the NP (Gilbert et al., 2013; Henriksson et al., 2011; Yim et al., 2014) have been tested. To date, however, only a limited number of regenerative therapies have entered the clinical 
phase as a treatment for human IVD degeneration (e.g. the Mesoblast study (allogeneic mesenchymal precursor cell (MPC) transplantation), http://clinicaltrials.gov/ show/:NCT00813813 (recombinant human growth and differentiation factor-5 (rhGDF-5)), NCT01640457 (NOVOCART $^{\circledR}$ disc plus autologous disc chondrocyte transplantation), NCT01771471 (allogenic juvenile chondrocytes (NuQu) transplantation), NCT01643681 (autologous adipose tissue derived MSC transplantation), NCT02338271 (autologous adipose tissue derived MSC transplantation), and the study by Mochida et al. (2015): MSC-activated CLC transplantation).

During IVD maturation, a transition in cell phenotype takes place from large, vacuolated notochordal cells (NCs) to smaller, non-vacuolated CLCs (Hunter et al., 2004; Purmessur et al., 2013b). During this process, the vacuolated NCs obtain a transitional phenotype, i.e. they maintain their size but do not contain vacuoles. Thereafter, they obtain a morphology of rounded CLCs. Early NC loss in certain species (e.g. chondrodystrophic dogs) coincides with the onset of IVD degeneration. NC-conditioned medium (NCCM, containing factors secreted by NCs) and $\mathrm{NC}$ :CLC co-culture stimulate in vitro differentiation of MSCs into a NP-like phenotype (de Vries et al., 2014; Korecki et al., 2010; Purmessur et al., 2011), protect the NP from apoptosis (Erwin et al., 2011; Mehrkens et al., 2013), and/or increase CLC proliferation and GAG production (Abbott et al., 2012; Aguiar et al., 1999; de Vries et al., 2014; Erwin and Inman, 2006; Erwin et al., 2006; Gantenbein et al., 2014; Potier et al., 2014). In addition, NCs significantly stimulate CLC activity and GAG production (Gantenbein-Ritter et al., 2012) and produce more GAGs than CLCs (Saggese et al., 2014). NCs have also been described to exert potential symptom modifying actions, e.g. anti-inflammatory, anti-neurogenic and antiangiogenic effects by secreting factors as sonic hedgehog, noggin, connective tissue growth factor and chondroitin sulphate (Cornejo et al., 2015; Gantenbein et al., 2014; Purmessur et al., 2013a). Thus, NCs secrete factors with auspicious potential, making them an interesting target for regenerative and/or symptom modifying therapies (Bach et al., 2014). NC-based regenerative strategies are being developed, using canine non-chondrodystrophic (NCD) and porcine donors because of easy availability of their NC-rich NP tissue (Bach et al., 2014). Although regenerative effects of canine and porcine $\mathrm{NC}$-secreted factors on human CLCs/MSCs have been demonstrated in several studies (Abbott et al., 2012; Korecki et al., 2010; Mehrkens et al., 2013; Purmessur et al., 2011), the impact of human NC-secreted factors has never been determined, most probably due to limited availability of human NC-rich NP tissue. It is, however, important to define if the human CLC response to homologous human NC-secreted factors is superior to canine and porcine NC-secreted factors. Therefore, the main aim of this study was to delineate whether secreted factors from NC-rich NP tissue from different species have a differential regenerative effect on human CLCs derived from degenerated IVDs. For this purpose, human, canine and porcine NC-rich NP tissue was cultured to generate NCCM. Given the differences in life span and in NC-maintenance with ageing between these species, it impossible to account for the ageing effect and distinguish it from the species-specific NCCM effect. Human CLCs derived from degenerated IVDs (Thompson grade III) were isolated and after expansion cultured in human, canine or porcine NCCM using a micro-aggregate culture system and compared with CLCs cultured in basal and chondrogenic culture medium.

\section{Materials and methods}

\section{NC-rich NP tissue sources}

IVD tissue (Thompson grade I) was collected from 12 human, 13 canine and 7 porcine donors. IVDs from human donors between 20 weeks of gestation and 3 months of age (postnatal) were obtained during a standard post mortem diagnostic procedure in which part of the spine was collected within $48 \mathrm{~h}$ after death, as approved by the scientific committee of the Pathology department of the University Medical Centre Utrecht. Anonymous use of redundant tissue for research purposes is a standard treatment agreement with patients in the University Medical Centre Utrecht (Local Medical Ethical Committee (METC) number 12-364). The material was used in line with the code 'Proper Secondary Use of Human Tissue' as installed by the Federation of Biomedical Scientific Societies. Complete canine spines (18-23 months of age) were collected from NCD dogs that had been euthanised in unrelated research studies (approved by the Utrecht University Animal Ethics Committee). Complete porcine spines ( 3 months of age) were collected from the slaughterhouse in accordance with local regulations. IVDs from all donors were opened under sterile conditions and NP tissue was collected by precise separation from the AF and cartilaginous endplates.

\section{DNA and extracellular matrix content of human, canine and porcine NC-rich NP tissue \\ Collagen, DNA and GAG content}

NC-rich NPs from 4 human (22 weeks of gestation, $3 \mathrm{~d}$, $5 \mathrm{~d}$ and 3 months of age), 21 canine (18-23 months of age) and 6 porcine ( 3 months of age) donors were used for histological and biochemical analysis. The human, canine and porcine NP tissue (naturally hydrated) was weighted using a microbalance. Papain digestion solution (pH 6, $200 \mathrm{mM} \mathrm{H}_{2} \mathrm{NaPO}_{4} * 2 \mathrm{H}_{2} \mathrm{O}$ (21254, Boom B.V., Meppel, the Netherlands), 10 mM EDTA (100944, Merck Millipore, Amsterdam, the Netherlands), $10 \mathrm{mM}$ cysteine $\mathrm{HCl}$ (C7880, Sigma-Aldrich, Saint Louis, USA), and $10 \mathrm{mM}$ papain (P3125, Sigma-Aldrich, Saint Louis, USA) was added to each NP, followed by overnight incubation at $60{ }^{\circ} \mathrm{C}$. The collagen content of NC-rich NP tissue was assessed using a hydroxyproline (HYP) assay (Neuman and Logan, 1950). Papain-digested NP samples were lyophilised for $1 \mathrm{~h}$ (Savant SpeedVac ${ }^{\circledR}$ System AES 2010 Concentrator) and hydrolysed overnight at $108{ }^{\circ} \mathrm{C}$ in $4 \mathrm{M} \mathrm{NaOH}$ (106498, Merck Millipore, Amsterdam, the Netherlands) in demineralised water. The samples were then centrifuged $(15 \mathrm{~s}$ at $14000 \times g)$ and incubated for 20 min with chloramine T reagent (2426, Merck Millipore, Amsterdam, the Netherlands). Thereafter, freshly prepared 
dimethylaminobenzaldehyde (DMAB; 103058, Merck Millipore, Amsterdam, the Netherlands) was added and the samples were incubated for $20 \mathrm{~min}$ at $60{ }^{\circ} \mathrm{C}$. The absorbance $(570 \mathrm{~nm})$ was read using a microplate reader (Model 3550, Bio-Rad, Veenendaal, the Netherlands). A linear standard line was generated with hydroxyproline (104506, Merck Millipore, Amsterdam, the Netherlands). The collagen content in the samples was calculated by multiplying the hydroxyproline content by 7.5 according to Neuman and Logan (1950). The DNA content per mg wet NP tissue was measured using the Qubit ${ }^{\circledR}$ dsDNA High Sensitivity Assay Kit (Q32851, Invitrogen, Paisley, UK) according to the manufacturer's instructions. To quantify the GAG content per mg wet NP tissue, a dimethyl methylene blue (DMMB) assay was performed (Farndale et al., 1982). Immediately after DMMB (341088, SigmaAldrich, Saint Louis, USA) was added, the absorbance $(540 / 595 \mathrm{~nm})$ was measured using a microplate reader. The GAG content was calculated using a chondroitin sulphate (C4384, Sigma-Aldrich, Saint Louis, USA) standard line with polynomic properties.

\section{Safranin O/Fast Green staining}

NP tissue was fixed in $4 \%$ neutral buffered formaldehyde (4286, Klinipath B.V., Duiven, the Netherlands) for $24 \mathrm{~h}$ at room temperature (RT) and embedded in paraffin. 5 - $\mu \mathrm{m}$ sections were mounted on Microscope KP + slides (KP-3056, Klinipath B.V., Duiven, the Netherlands) and deparaffinised through xylene (two times $5 \mathrm{~min}$ ) and graded ethanol (96\%, $80 \%, 70 \%, 60 \%$; 5 min each), followed by one PBS rinse. The sections were subjected to Mayer's haematoxylin (3870, J.T.Baker ${ }^{\circledR}$ Chemicals - Avantor Performance Materials, Center Valley, USA) for $10 \mathrm{~s}$ and rinsed with demineralised water for $5 \mathrm{~min}$. Subsequently, the sections were counterstained with filtered $0.4 \%$ Fast Green (F7252, Sigma-Aldrich, Saint Louis, USA) for $4 \mathrm{~min}$, subjected to $1 \%$ acetic acid for two times $3 \mathrm{~min}$, and stained with $0.125 \%$ aqueous Safranin O (58884, SigmaAldrich, Saint Louis, USA) for $7 \mathrm{~min}$. The sections were then dehydrated with $100 \%$ ethanol (2 min) and xylene (two times $5 \mathrm{~min}$ ) and mounted (Vectamount, H5000, Vector Laboratories, Burlingame, USA).

\section{Collagen type I and II immunohistochemistry}

For collagen type II immunohistochemistry (IHC), the sections were deparaffinised (see previously). Thereafter, they were blocked for $10 \mathrm{~min}$ with $0.3 \% \mathrm{H}_{2} \mathrm{O}_{2}$ (51008600.9025, Boom B.V., Meppel, the Netherlands) and washed three times for 5 min with PBS $+0.1 \%$ Tween (PBST0.1\%). Antigen retrieval was performed with $1 \mathrm{mg} /$ $\mathrm{mL}$ pronase (11459643001, Roche Diagnostics, Almere, the Netherlands) and $10 \mathrm{mg} / \mathrm{mL}$ hyaluronidase (H3506, Sigma-Aldrich, Saint Louis, USA) in PBS for $30 \mathrm{~min}$ at $37{ }^{\circ} \mathrm{C}$. After washing with PBST0.1\%, the sections were blocked with $5 \%$ BSA in PBS for 30 min at $37^{\circ} \mathrm{C}$. Thereafter, they were incubated overnight at $4{ }^{\circ} \mathrm{C}$ with collagen type II mouse monoclonal antibody $(0.4 \mu \mathrm{g} /$ $\mathrm{mL}$, II-II6B3, DSHB, Iowa City, IA) in $5 \%$ BSA in PBS. In control staining, the first antibody was substituted with normal mouse $\operatorname{IgG}_{1}(0.4 \mu \mathrm{g} / \mathrm{mL} ; 3877$, Santa Cruz
Biotechnology, Heidelberg, Germany). These negative controls showed no aspecific positive staining. The next day, the sections were washed with PBST0.1\% before the secondary antibody (EnVision + System-HRP Goat Anti-Mouse, K4001, Dako, Glostrup, Denmark) was applied for $60 \mathrm{~min}$ at RT. After washing with PBS, the sections were incubated with the liquid DAB substrate chromogen system (K3468, Dako, Glostrup, Denmark) for $10 \mathrm{~min}$ and counterstained with haematoxylin QS solution (H3404, Vector Laboratories, Burlingame, USA) for $1 \mathrm{~min}$. Thereafter, they were washed with tap water for $10 \mathrm{~min}$ and dehydrated with graded ethanol $(70 \%, 80 \%, 96 \%$ and $100 \%$ ) and xylene (two times $5 \mathrm{~min}$ ) and mounted. For collagen type I IHC, the same procedures were followed with the Anti-Collagen I antibody $(0.1 \mu \mathrm{g} / \mathrm{mL}$, ab6308, Abcam, Cambridge, UK).

\section{Generation and analysis of species-specific NCCM Generation of NCCM}

Conditioned medium was generated from NC-rich NP tissue (Thompson grade I) of 10 human, 4 canine and 4 porcine donors (Table 1). The NP tissue was cultured for $4 \mathrm{~d}(1 \mathrm{~g}$ tissue $/ 30 \mathrm{~mL})$ in hgDMEM+Glutamax (31966, Invitrogen, Paisley, UK) with $1 \%$ P/S (P11-010, GE Healthcare Life Sciences, Eindhoven, the Netherlands) at $37{ }^{\circ} \mathrm{C}, 5 \% \mathrm{CO}_{2}$ and $5 \% \mathrm{O}_{2}$ (hypoxic; 6 human donors and all canine/porcine donors) or $21 \% \mathrm{O}_{2}$ (normoxic; 4 human donors) using a Sanyo MCO-18M incubator. After $4 \mathrm{~d}$, the $\mathrm{NP}$ tissue was removed and the $\mathrm{NC}$-conditioned medium was filtered through a $70 \mu \mathrm{m}$ cell strainer. The filtrate was sequentially centrifuged at $200 \times g$ and $500 \times g(2 \times$ $10 \mathrm{~min}, 4^{\circ} \mathrm{C}$ ) to remove (dead) cells and debris. Thereafter, the supernatant containing the cell-free conditioned medium was concentrated using a $3 \mathrm{kDa}$ Amicon Ultra-15 Centrifugal filter tube (Merck Millipore, Amsterdam, the Netherlands) at $4000 \times g\left(45 \mathrm{~min}, 4^{\circ} \mathrm{C}\right)$. All substances with a molecular weight $>3 \mathrm{kDa}$ were resuspended in fresh hgDMEM+Glutamax and stored in aliquots at $-70{ }^{\circ} \mathrm{C}$ until use. $\mathrm{Per}$ canine and porcine donor, about $100 \mathrm{~mL}$ NCCM was generated from all harvested NPs. The human NPs, however, were very small and only 2-3 NPs were available per donor, resulting on average in $1 \mathrm{~mL} \mathrm{NCCM}$ per donor. Due to volume limitations, the hypoxic NCCM of 4 human donors (20-21 weeks of gestation) were pooled $(2 \times 2$ donors, Table 1$)$ to perform the complete in vitro study design. Eventually, 4 normoxic (all separate) and 4 hypoxic ( 2 separate and 2 pooled) human NCCM donors were used in the culture experiments.

\section{Collagen, GAG, and protein concentration of species- specific NCCM}

Filtrated, cell (debris)-free NCCM from 7 human (21 weeks of gestation - 3 months of age), 7 canine (18-23 months of age) and 7 porcine ( 3 months of age) donors were biochemically analysed. A HYP and DMMB assay were performed as described above. To determine the NCCM protein concentration, the Qubit ${ }^{\circledR}$ Protein Assay Kit (Q33211, Invitrogen, Paisley, UK) was used according to the manufacturer's instructions. 
Table 1. Human, canine and porcine notochordal cell-conditioned medium (NCCM) donor characteristics.

\begin{tabular}{|c|c|c|c|c|c|c|c|}
\hline Species & HX/NX & Thompson grade & Level & Donor number & $n$ & Donor age & Life span (y) \\
\hline \multirow{4}{*}{ Human } & \multirow{4}{*}{ HX } & \multirow{4}{*}{ 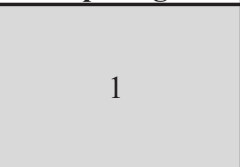 } & \multirow{4}{*}{ L2-L5 } & 1 & 2 (pooled) & 20 weeks of gestation & \multirow{4}{*}{80} \\
\hline & & & & 2 & 2 (pooled) & 21 weeks of gestation & \\
\hline & & & & 3 & 1 & 1 days & \\
\hline & & & & 4 & 1 & 6 days & \\
\hline \multirow{4}{*}{ Human } & \multirow{4}{*}{ NX } & \multirow{4}{*}{1} & \multirow{4}{*}{ L2-L5 } & 5 & 1 & 2 days & \multirow{4}{*}{80} \\
\hline & & & & 6 & 1 & 3 days & \\
\hline & & & & 7 & 1 & 5 days & \\
\hline & & & & 8 & 1 & 3 months & \\
\hline \multirow{4}{*}{ Canine } & \multirow{4}{*}{ HX } & \multirow{4}{*}{1} & \multirow{4}{*}{$\begin{array}{l}\text { Whole spine } \\
\text { (C2-S1) }\end{array}$} & 1 & 1 & 18 months & \multirow{4}{*}{$10-15$} \\
\hline & & & & 2 & 1 & 23 months & \\
\hline & & & & 3 & 1 & 20 months & \\
\hline & & & & 4 & 1 & 18 months & \\
\hline \multirow{4}{*}{ Porcine } & \multirow{4}{*}{ HX } & \multirow{4}{*}{1} & \multirow{4}{*}{$\begin{array}{l}\text { Whole spine } \\
\text { (C2-S1) }\end{array}$} & 1 & 1 & 3 months & \multirow{4}{*}{$10-20$} \\
\hline & & & & 2 & 1 & 3 months & \\
\hline & & & & 3 & 1 & 3 months & \\
\hline & & & & 4 & 1 & 3 months & \\
\hline
\end{tabular}

NCCM was generated from NC-rich NP tissue of 10 human, 4 canine and 4 porcine donors. $n$ : number of individuals from which NP tissue was used to generate NCCM; HX: NCCM generated under hypoxic $\left(5 \% \mathrm{O}_{2}\right)$ conditions; NX: NCCM generated under normoxic $\left(21 \% \mathrm{O}_{2}\right)$ conditions. The species life span of the canine and porcine donors depends upon the breed.

\section{In vitro micro-aggregate culture of human CLCs derived from degenerated IVDs}

CLCs of 3 human donors ( 2 females and 1 male, age range 47-63 y) were obtained from IVDs scored as Thompson grade III. These IVDs were obtained during a standard post mortem diagnostic procedure in which part of the spine was collected within $48 \mathrm{~h}$ after death, as approved by the scientific committee of the Pathology department of the University Medical Centre Utrecht. Anonymous use of redundant tissue for research purposes is a standard treatment agreement with patients in the University Medical Centre Utrecht (Local Medical Ethical Committee (METC) number 12-364). The material was used in line with the code 'Proper Secondary Use of Human Tissue' as installed by the Federation of Biomedical Scientific Societies. The CLCs were expanded in expansion medium containing hgDMEM+Glutamax with $10 \%$ FBS (Gibco 16000-044, Life Technologies, Bleiswijk, the Netherlands), $1 \% \mathrm{P} / \mathrm{S}, 0.1 \mathrm{mM}$ Ascorbic acid 2-phosphate (A8960, Sigma-Aldrich, Saint Louis, USA), $10^{-9} \mathrm{M}$ dexamethasone (AD1756, Sigma-Aldrich, Saint Louis, USA) and $1 \mathrm{ng} /$ mL bFGF (PHP105, AbD Serotec, Puchheim, Germany) at $21 \% \mathrm{O}_{2}, 5 \% \mathrm{CO}_{2}, 37{ }^{\circ} \mathrm{C}$. Medium was changed twice weekly. After the CLCs reached $90 \%$ confluence in P2, they were pooled and micro-aggregates of 35,000 cells were formed (day 0). In the experimental setup, human CLCs were pooled (a) due to volume limitations of the available human NCCM and (b) in order to specifically assess the effect of donor-specific NCCM on a representative human CLC population that was derived from degenerated IVDs. The pooled CLCs were plated in low-adherence cellrepellent surface 96-well plates $\left(650970\right.$, CELLSTAR ${ }^{\circledR}$ Greiner Bio-one, Alphen a/d Rijn, the Netherlands) in $50 \mu \mathrm{L}$ basal culture medium: hgDMEM+Glutamax with $1 \% \mathrm{P} / \mathrm{S}, 1 \% \mathrm{ITS}+\operatorname{premix}$ (354352, Corning Life Sciences,
Amsterdam, the Netherlands), $0.04 \mathrm{mg} / \mathrm{mL}$ L-proline (P5607, Sigma-Aldrich, Saint Louis, USA), $0.1 \mathrm{mM}$ Ascorbic acid 2-phosphate, and $1.25 \mathrm{mg} / \mathrm{mL}$ Human Serum Albumin (HSA, Sanquin Research, Amsterdam, the Netherlands). The 96-well plates were centrifuged at $50 \times g$ for $5 \mathrm{~min}$ to induce micro-aggregate formation. The next day, basal culture medium was replaced with either basal culture medium for the negative control micro-aggregates, chondrogenic culture medium (basal culture medium supplemented with $10 \mathrm{ng} / \mathrm{mL}$ human recombinant TGF- $\beta_{1}$ (240-B, R\&D Systems, Inc., Minneapolis, USA)) for the positive control micro-aggregates or human/canine/porcine NCCM supplemented with $1 \% \mathrm{P} / \mathrm{S}, 1 \%$ ITS + premix, $0.04 \mathrm{mg} / \mathrm{mL}$ L-proline, $0.1 \mathrm{mM}$ ascorbic acid 2-phosphate, and $1.25 \mathrm{mg} / \mathrm{mL} \mathrm{HSA}$. The micro-aggregates were cultured for $28 \mathrm{~d}$ in $21 \% \mathrm{O}_{2}, 5 \% \mathrm{CO}_{2}, 37^{\circ} \mathrm{C}$.

\section{Cell proliferation and extracellular matrix production of the human CLC micro-aggregates} The effect of washing NCCM-treated micro-aggregates Given that NCCM contains a high GAG concentration which could attach to the micro-aggregates (resulting into a false positive high GAG content), human CLC microaggregates cultured for $7 \mathrm{~d}$ in canine $\operatorname{NCCM}(n=4)$ were $0,1,2$ or 3 times incubated in $1 \mathrm{~mL}$ Hanks Balanced Salt Solution (HBSS, 14024, Life Technologies, Bleiswijk, the Netherlands) for $1 \mathrm{~min}$ to determine whether washing decreased the measured GAG content of the microaggregates.

\section{Collagen, DNA and GAG content}

At day 28, the collagen content, and at day 0, 14 and 28, the DNA and GAG content of the human CLC microaggregates were determined as described above $(n=8-16$ per condition). The micro-aggregates were washed 
three times with $1 \mathrm{~mL}$ HBSS to remove any residual (conditioned) medium, lyophilised for $1 \mathrm{~h}$, and stored $\left(-20{ }^{\circ} \mathrm{C}\right)$ until use. GAG release into the NCCM culture medium could not be determined due to extremely high NCCM GAG concentrations compared with the GAG release by the micro-aggregates.

\section{Histology}

At day 28, the micro-aggregates were fixed for $24 \mathrm{~h}$ in $4 \%$ neutral buffered formaldehyde containing $1 \%$ eosin (115935, Merck Millipore, Amsterdam, the Netherlands) to be able to detect them during the cutting process. The next day, the micro-aggregates were embedded in one drop of $2.4 \%$ alginate (A2033, Sigma-Aldrich, Saint Louis, USA) and paraffin. 5- $\mu \mathrm{m}$ sections were stained with Safranin O/ Fast Green as described above, preceded by incubation in citrate (100244, Merck Millipore, Amsterdam, the Netherlands) buffer (10 mM, $0.05 \%$ Tween, $\mathrm{pH}$ 6) for $15 \mathrm{~min}$ at RT to ensure alginate removal. IHC staining for collagen type I and II was performed as described previously. For collagen type X immunohistochemistry, antigen retrieval was performed with $0.5 \%$ pepsin in PBS (S3002, Dako, Glostrup, Denmark) for $20 \mathrm{~min}$ at $37^{\circ} \mathrm{C}$ and $10 \mathrm{mg} / \mathrm{mL}$ hyaluronidase in PBS $\left(30 \mathrm{~min}, 37^{\circ} \mathrm{C}\right)$. The sections were blocked at RT with Dual Endogenous Enzyme-Blocking Reagent (S2003, Dako, Glostrup, Denmark) and goat serum (5 and $30 \mathrm{~min}$, respectively). Thereafter, the sections were incubated overnight at $4{ }^{\circ} \mathrm{C}$ with 1:50 diluted primary Collagen Type $\mathrm{X}$ antibody (2031501005, Quartett, Berlin, Germany). In control staining, the primary antibody was substituted with normal mouse $\operatorname{IgG}_{1}(4 \mu \mathrm{g} / \mathrm{mL}$; 3877, Santa Cruz Biotechnology, Heidelberg, Germany). These negative controls showed no aspecific positive staining. The next day, sections were washed with PBST0.1\% before the secondary antibody (EnVision+ System-HRP Goat Anti-Mouse, K4001, Dako, Glostrup, Denmark) was applied (30 min, RT). After washing with PBS, the sections were incubated with the liquid DAB substrate chromogen system, counterstained with haematoxylin QS solution, washed with tap water, dehydrated and mounted (see above).

Gene expression of the human CLC micro-aggregates In order to study the transcriptional response of CLCs to NCCM at day 7 , micro-aggregates ( $n=6$ per condition) were frozen in liquid nitrogen and crushed using pestles (P9951-901, Argos Technologies, Elgin, USA). RNA was extracted with the RNeasy ${ }^{\circledR}$ Micro kit (74004, Qiagen, Valencia, USA) according to the manufacturer's instructions. A DNAse (RNAse-Free DNase Set, 79254, Qiagen, Valencia, USA) step was included to ensure DNA removal. The quality of the isolated RNA was assessed with an Agilent 2100 Bioanalyser and RNA Nanochip kit (5067-1511, Agilent Technologies, Amstelveen, the Netherlands). cDNA was synthesised using the iScript ${ }^{\mathrm{TM}}$ cDNA Synthesis Kit (170-8891, Bio-Rad, Veenendaal, the Netherlands) according to the manufacturer's instructions. Primer sequences were designed using PerlPrimer (http://perlprimer.sourceforge.net) or obtained from previous work (Supplementary file). M-fold was used to check for secondary structure formation (Zuker, 2003).
Primer uniqueness and specificity was determined using BLAST (Altschul et al., 1997). Annealing temperatures were established by performing a temperature gradient PCR on a 16 -fold dilution series. The four most stably expressed reference genes (TATAA-box binding protein $(T B P)$, hypoxanthine-guanine phosphoribosyltransferase (HPRT), succinate dehydrogenase subunit A (SDHA) and tyrosine 3-monooxygenase/tryptophan 5-monooxygenase activation protein, zeta polypeptide (YWHAZ)) were chosen to normalise gene expression of the target genes (aggrecan $(A C A N)$, a disintegrin and metalloproteinase with thrombospondin motifs 5 (ADAMTS5), Bcl2like-protein $(B A X)$, B-cell CLL/lymphoma $2(B C L-2)$, caspase-3 (CASP3), collagen type I (COL1A1), collagen type II (COL2A1), collagen type X (COL10A1), cyclin $\mathrm{D} 1$ (CCND1) and matrix metalloproteinase 13 (MMP13)). RT-qPCR was performed using the iQT ${ }^{\mathrm{TM}}$ SYBR Green Supermix Kit (Bio-Rad, Veenendaal, the Netherlands) and the CFX384 Touch $^{\mathrm{TM}}$ Real-Time PCR Detection System (Bio-Rad, Veenendaal, the Netherlands). For determination of relative quantitative gene expression, the Normfirst $\left(\mathrm{E}^{\Delta \Delta \mathrm{Cq}}\right)$ method was used. For each target gene, the Cqvalue of the test sample and the calibrator sample was normalised to the mean $\mathrm{Cq}$-value of the reference genes: $\Delta \mathrm{Cq}=\mathrm{Cq}_{\text {mean ref }}-\mathrm{Cq}_{\text {target }}$. Cq-values of the negative control micro-aggregates were used as calibrator. Secondly, the $\mathrm{E}^{\Delta \mathrm{Cq}}$-value for the test and calibrator sample was calculated. In this formula, $\mathrm{E}$ indicates the amplification efficiency of the target/reference gene. $\mathrm{E}^{\Delta \Delta \mathrm{Cq}}$ was calculated by normalising the $\mathrm{E}^{\Delta \mathrm{Cq}}$-value of the test sample to the one of the calibrator: $\mathrm{E}^{\Delta \Delta \mathrm{Cq}}=\mathrm{E}^{\Delta \mathrm{Cq} \text { test }}-\mathrm{E}^{\Delta \mathrm{Cq} \text { calibrator. }}$. For each target gene, the mean $n$-fold changes and standard deviations in gene expression were calculated.

\section{Statistical analysis}

All statistical analyses were performed using IBM SPSS statistics 22. First, the data were examined for normal distribution using a Shapiro Wilks test. A Kruskal Wallis and Mann-Whitney U test were performed on non-normally distributed data, whereas general linear regression models based on ANOVAs were used for normally distributed data. All tests were followed by a Benjamini \& Hochberg False Discovery Rate post-hoc test for multiple comparisons. A $p$-value $<0.05$ was considered significant.

\section{Results}

\section{Analysis of human, canine and porcine NC-rich NP tissue and species-specific NCCM}

To characterise the species-specific NP tissue where the NCCM was generated from, the histological phenotype of the NC-rich NP tissue was determined. It appeared comparable in all human donors under 3 months. Healthy canine and porcine NP tissue contained considerably more typical large, vacuolated NCs than human NP tissue, which contained large areas of extracellular matrix with relatively few cells (Fig. 1). Scattered throughout the human NP, cells with a transitional phenotype (large, non-vacuolated cells) or CLC phenotype (small, non-vacuolated cells with little 


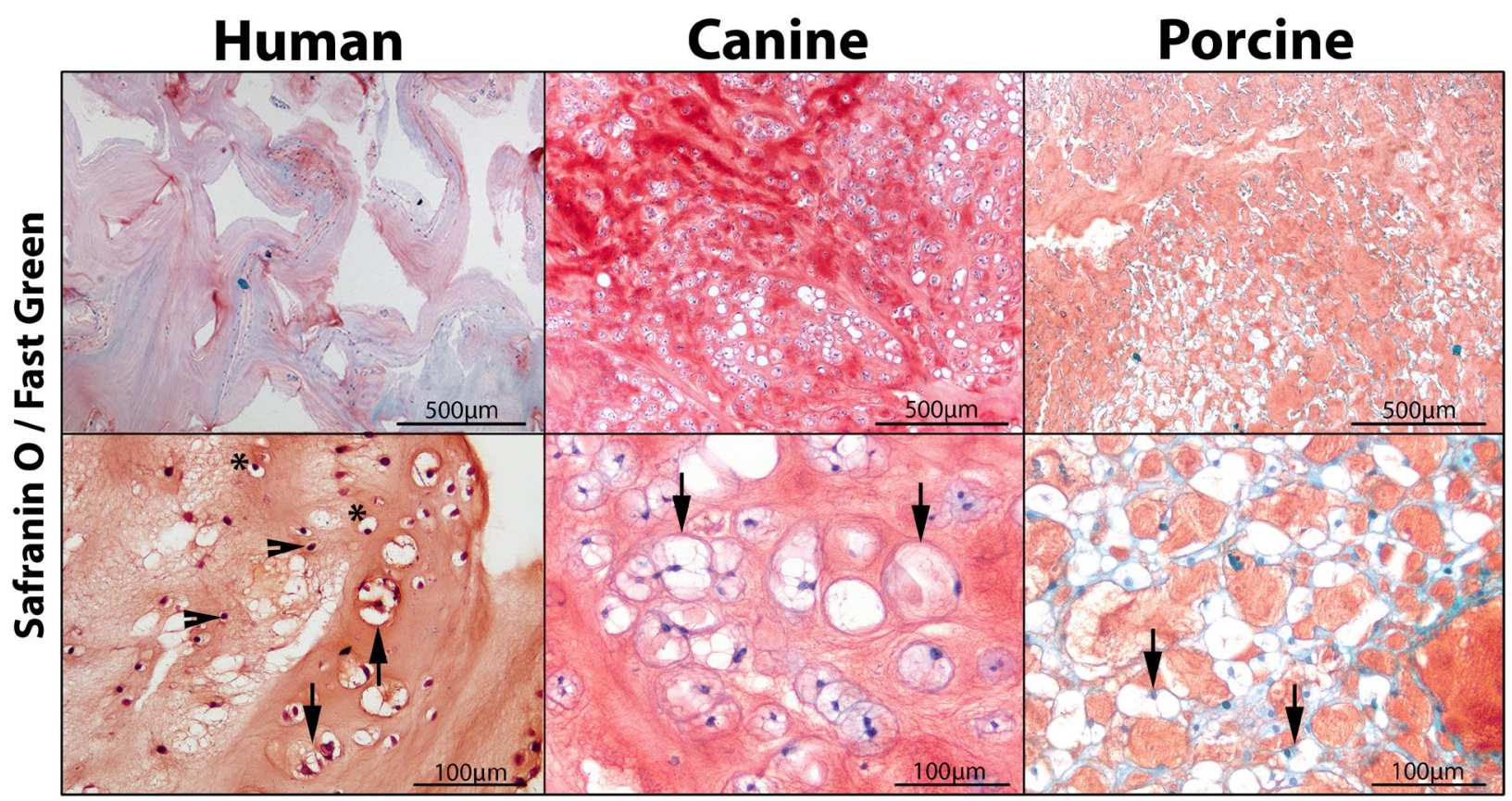

Fig. 1. Canine and porcine nucleus pulposus (NP) tissue contains typical notochordal cells (NCs), whereas human NP tissue contains more cells with a transitional phenotype and chondrocyte-like cells (CLCs). Safranin O/Fast Green staining of representative human ( $3 \mathrm{~d}$ of age), canine (18 months of age) and porcine ( 3 months of age) NP tissue obtained from IVDs with Thompson grade I. The lower panel shows the NP cellular phenotype in more detail. Arrows indicate typical large vacuolated NCs, arrowheads indicate typical smaller non-vacuolated CLCs and stars indicate the transitional cell phenotype found in human NP tissue.
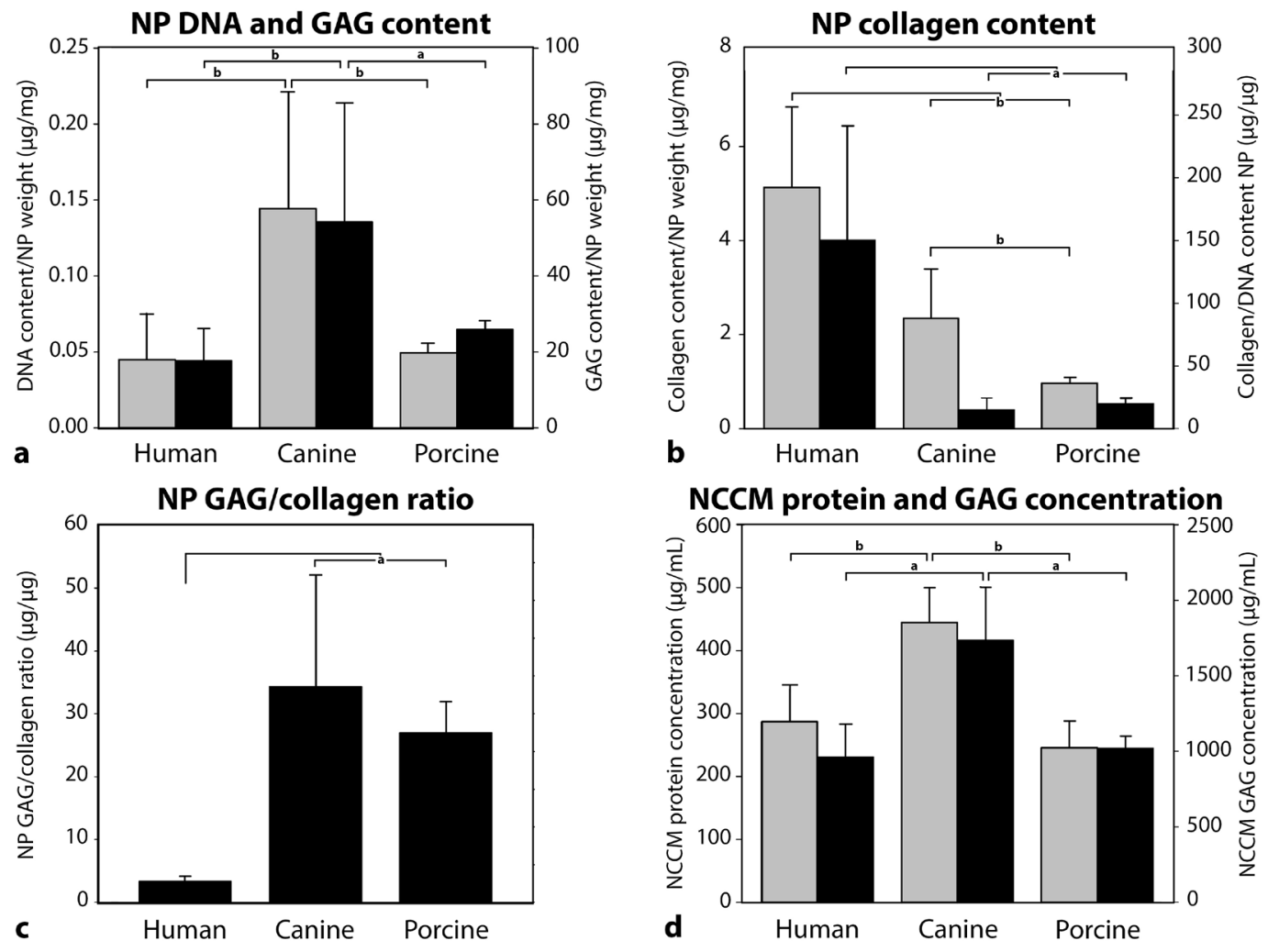

Fig. 2. Canine nucleus pulposus (NP) tissue contains the highest DNA and GAG content, whereas human NP tissue contains the highest collagen content. Biochemical differences between human, canine and porcine NC-rich NP tissue (Thompson grade I) and NC-conditioned medium (NCCM). (a) The DNA (grey bar) and GAG (black bar) content (mean $\pm \mathrm{SD}$ ) of NC-rich human, canine and porcine NP tissue. (b) The collagen content (mean $\pm \mathrm{SD}$ ) of NC-rich human, canine and porcine NP tissue per mg wet NP weight (grey bar) and per DNA content of the NP tissue (black bar). (c) The $\mathrm{GAG}$ /collagen ratio (mean $\pm \mathrm{SD}$ ) of NC-rich human, canine and porcine NP tissue. (d) The protein (grey bar) and GAG (black bar) concentration (mean $\pm \mathrm{SD}$ ) of human, canine and porcine NCCM. a: $p<0.05 ; b: p<0.01 ; n=4$ (human), 21 (canine) and 6 (porcine) for NC-rich NP tissue and $n=7$ (all species) for NCCM analysis. 


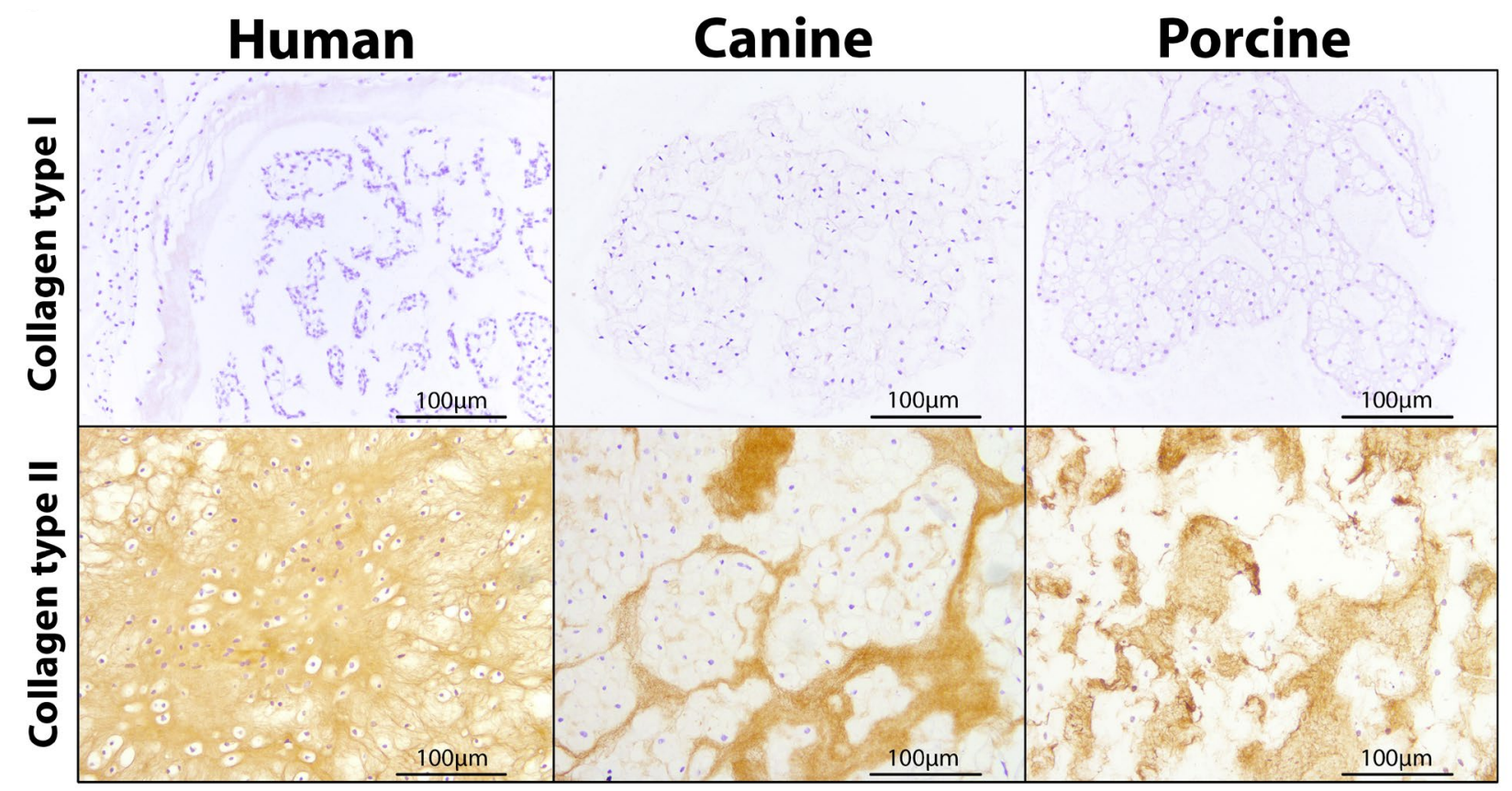

Fig. 3. Human, canine and porcine nucleus pulposus (NP) tissue contains collagen type II but no collagen type I protein. Collagen type I and II protein expression of representative human (foetal, 21 weeks of gestation), canine (18 months of age) and porcine ( 3 months of age) NPs obtained from IVDs with Thompson grade I.

cytoplasm) were present. NCs were only scarcely present and were predominantly positioned in cell clusters.

The GAG and DNA content per mg wet canine NCrich NP tissue was significantly higher than that of human and porcine NC-rich NP tissue (Fig. $2 \mathrm{a} ; \mathrm{p}<0.05$ ). The GAG content corrected for the DNA content of the human, canine and porcine NP tissue, however, was comparable for all species (data not shown). NC-rich human NP tissue contained significantly more collagen (per mg wet NP weight and per $\mu \mathrm{g}$ DNA of the NP) than NC-rich canine and porcine NP tissue (Fig. $2 \mathrm{~b} ; p<0.05$ ). In line with these results, the GAG/collagen ratio was significantly lower in the human than in the canine and porcine NC-rich NP (Fig. 2c; $p<0.05$ ). Canine NC-rich NP tissue contained significantly more collagen per $\mathrm{mg}$ wet tissue than porcine NC-rich NP tissue $(p<0.01)$, but not more collagen per DNA content of the NP (Fig. 2b). Additionally, there was no statistically significant difference in the GAG/collagen ratio between canine and porcine NC-rich NPs (Fig. 2c). In the foetal human NP tissues, the GAG: collagen ratio was 3.4:1, which equals a GAG: hydroxyproline ratio of $25: 1$. The latter is in line with previous findings in healthy 2- to 5-year-old human donors, in which the NP GAG: hydroxyproline ratio was $25: 1$, whereas it was $2: 1$ in the $\mathrm{AF}$ and 3:1 in the cartilaginous endplate (Mwale et al., 2004). Collagen type II protein was abundantly present in the extracellular matrix of the NP of all donors, regardless the donors species and age, whereas collagen type I was not expressed within the NP (Fig. 3). Thus, in the present study, human NP tissue was successfully separated from AF tissue and that solely the effect of species-specific NPsecreted factors was compared, without interference from $\mathrm{AF}$ and/or endplate-secreted substances.
The protein and GAG concentration of human and porcine NCCM was comparable and significantly lower than that of canine NCCM (Fig. $2 \mathrm{~d} ; p<0.05$ ). Collagen was undetectable in NCCM of all tested species (data not shown).

\section{In vitro effects of species-specific NCCM on human CLCs derived from degenerated IVDs}

Since NCCM contains a high GAG concentration that could attach to the outer layer of the micro-aggregates (resulting in an overestimation of the micro-aggregate GAG content), micro-aggregates were washed (1 min in $1 \mathrm{~mL} \mathrm{HBSS}$ ) to investigate whether this would result into a lower GAG content. Washing the micro-aggregates one or two times resulted into a significantly lower GAG/ DNA content ( $p<0.05$; Fig. 4 g). There was no significant difference in GAG/DNA content between micro-aggregates that were washed two or three times.

No significant differences were detected in DNA, GAG and GAG/DNA content of micro-aggregates cultured in human NCCM generated under normoxic (NX) and hypoxic (HX) conditions (Fig. 4a-c), suggesting that oxygen status during NCCM generation does not result into a differential biologic activity on human CLCs. Therefore, the results of these two NCCM conditions were pooled in the rest of the study. The DNA content of the human CLC micro-aggregates decreased over time in every culture condition, except for canine NCCM ( $p<0.05$; Fig. 4d). Although not as distinct as TGF- $\beta$ treatment, NCCM from all species significantly increased the DNA content of the micro-aggregates compared with controls $(p<0.001$; Fig. $4 d)$. The DNA content of the micro-aggregates cultured in human NCCM was significantly lower than those cultured 

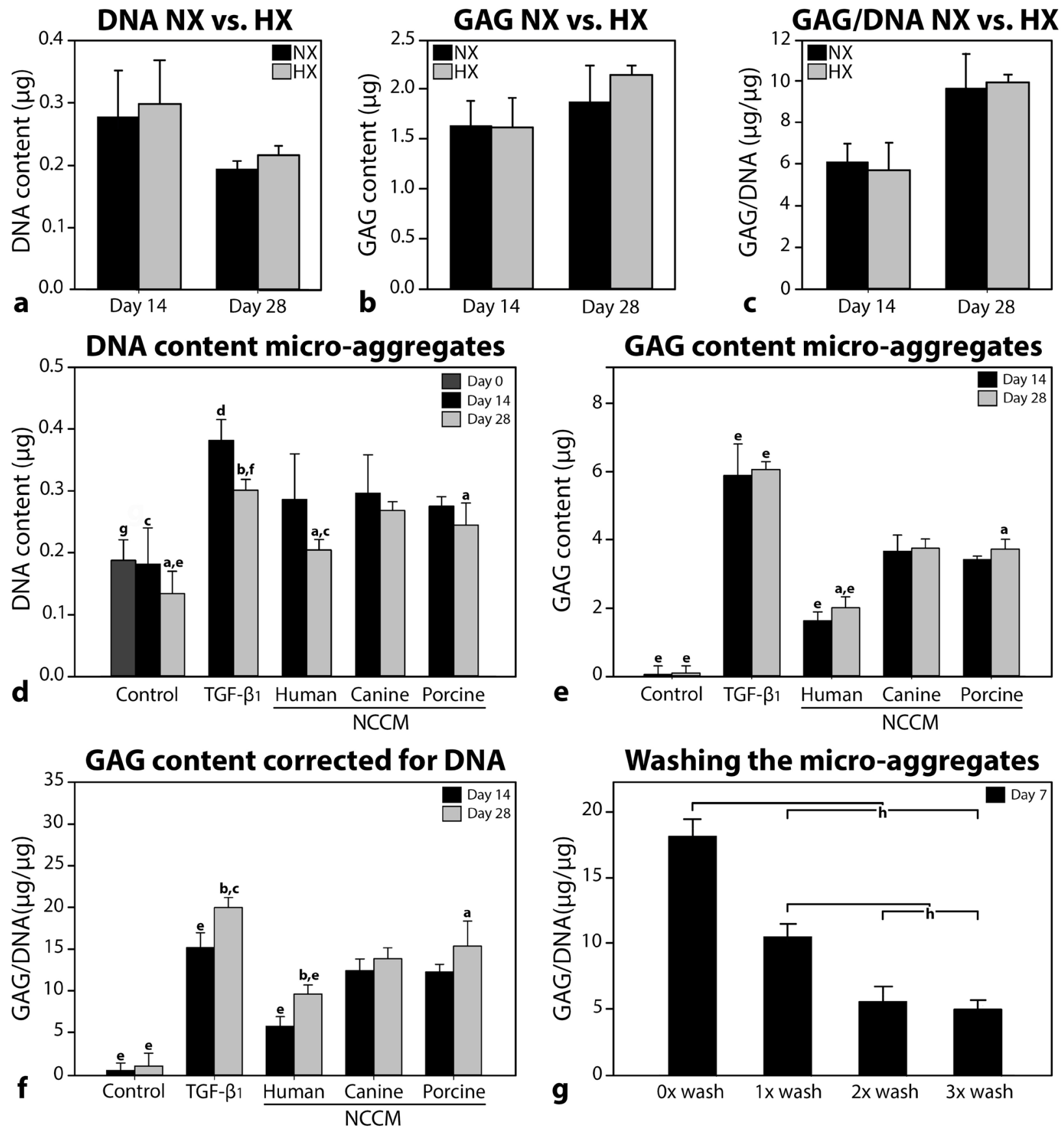

Fig 4. NC-conditioned medium (NCCM) derived from human, canine and porcine donors exerts regenerative effects on human chondrocyte-like cells (CLCs) derived from degenerated intervertebral discs (IVDs). Cell proliferation and matrix production of human CLCs derived from degenerated IVDs cultured in micro-aggregates in basal culture medium (control), chondrogenic culture medium (with $10 \mathrm{ng} / \mathrm{mL} \mathrm{TGF-} \beta_{1}$ ) and NC-conditioned medium (NCCM) of different species. (a-c) DNA, GAG and GAG/DNA content (mean \pm SD) of human CLC micro-aggregates cultured in human NCCM generated under normoxic (NX, $21 \% \mathrm{O}_{2}$ ) or hypoxic $\left(\mathrm{HX}, 5 \% \mathrm{O}_{2}\right)$ conditions for $28 \mathrm{~d}$. $n=4$ per condition. (d-f) DNA, GAG and GAG/DNA content (mean \pm SD) of human CLC micro-aggregates at day 14 and 28 of culture. $n=8$-16 per condition. (g) GAG/DNA content (mean \pm SD) of human CLC micro-aggregates cultured in canine NCCM for $7 \mathrm{~d}$ washed $0,1,2$ or 3 times with $1 \mathrm{~mL}$ PBS. $n=4$. Human: human NCCM (NX and HX, pooled); Canine: canine NCCM (HX); Porcine: Porcine NCCM (HX); a, b: significant difference between day 14 and 28 in this condition ( $p<0.05$ and $p<0.01$, respectively); c, d, e: significant difference between this condition and all other conditions at this time point ( $p<0.05, p<0.01$, and $p<0.001$, respectively); f: significantly different compared with porcine NCCM $(p<0.001)$; g: significantly different from the TGF- $\beta_{1}$, human, canine and porcine NCCM condition at day 14 and the TGF- $\beta_{1}$ condition at day $28 ; \mathrm{h}: p<0.05$. 


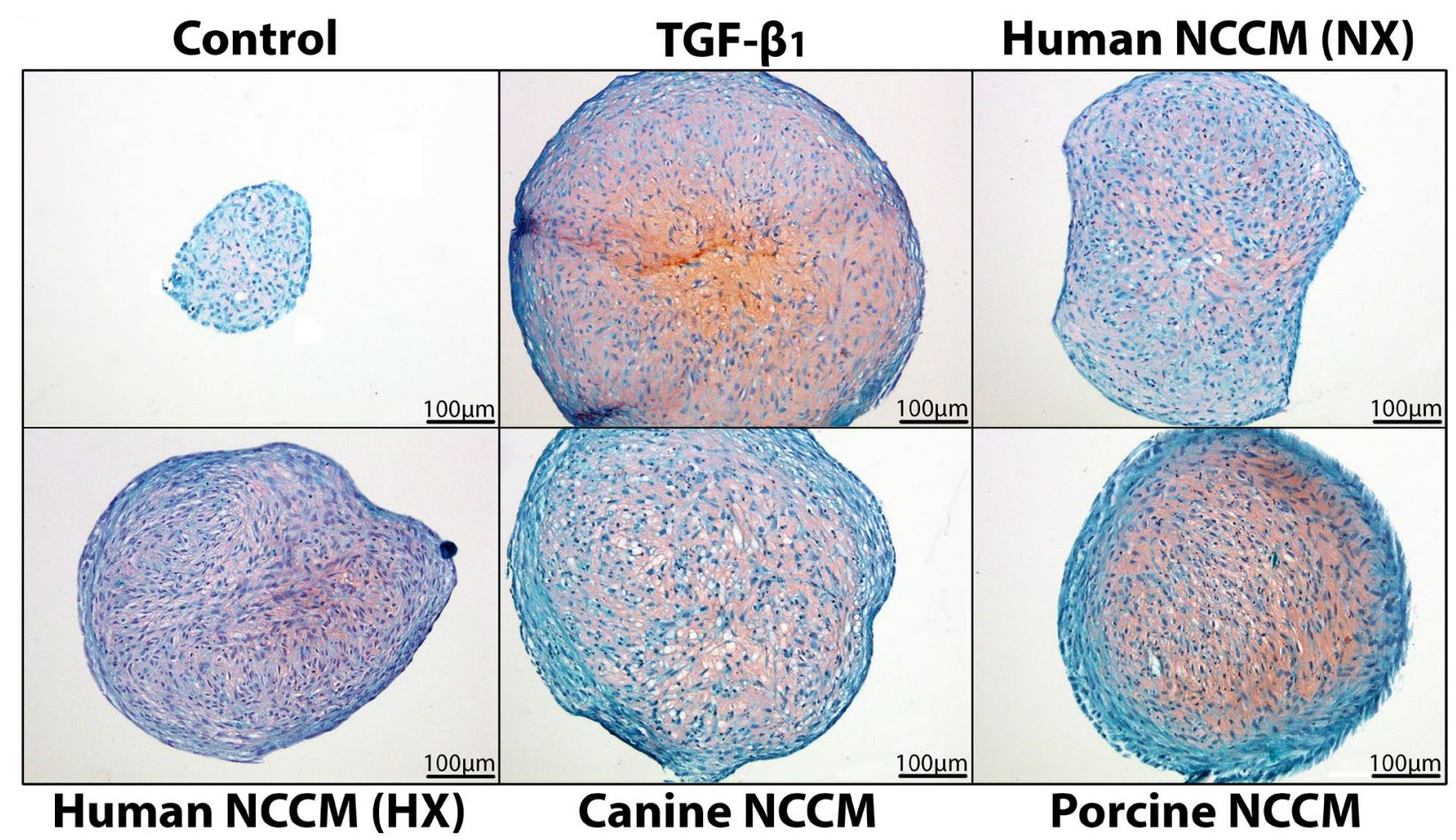

Fig. 5. NC-conditioned medium (NCCM) derived from human, canine and porcine donors induces GAG deposition in human chondrocyte-like cells (CLCs) derived from degenerated intervertebral discs (IVDs). Safranin O/Fast Green staining of human CLCs derived from degenerated IVDs cultured in micro-aggregates in basal culture medium (control), chondrogenic culture medium (with $10 \mathrm{ng} / \mathrm{mL}$ TGF- $\beta_{1}$ ) and NC-conditioned medium (NCCM) of different species for $28 \mathrm{~d}$. Red staining indicates GAG-rich matrix deposition. NX: Human NCCM generated under normoxic conditions $\left(21 \% \mathrm{O}_{2}\right)$; HX: Human NCCM generated under hypoxic conditions $\left(5 \% \mathrm{O}_{2}\right)$. Canine and porcine NCCM was generated under hypoxic conditions.

in canine and porcine NCCM $(p<0.05$; Fig. $4 d)$. NCCM from all species significantly increased the GAG and GAG/ DNA content of the micro-aggregates compared with untreated CLCs ( $p<0.001$; Fig. 4e and 4f). Although not as potent as TGF- $\beta_{1}$ treatment, canine and porcine NCCM were significantly more potent than human NCCM in inducing GAG deposition by human CLCs $(p<0.001$, Fig. 4e and 4f).

Safranin O/Fast Green staining indicated that GAGs were present in all NCCM-treated micro-aggregates (Fig. 5). A fibrotic rim that did not stain positive for GAGs was visible around the micro-aggregates treated with TGF- $\beta_{1}$, canine and porcine NCCM, but was less prominent in human NCCM (Fig. 5). In line with these results, COL1A1 gene expression was significantly increased in these conditions compared with human NCCM and controls $(p<0.001$; Fig. 6a). Moreover, collagen type I protein was abundantly present in TGF- $\beta_{1}$-treated micro-aggregates, and in lower amounts in canine and porcine NCCMtreated micro-aggregates (Fig. 6b). The HYP assay was not sensitive enough to determine the collagen content of the micro-aggregates.

Although the micro-aggregates that were cultured in NCCM of all species demonstrated an increased GAG content (Fig. 4e), ACAN and COL2A1 gene expression was not upregulated in these conditions compared with controls at day 7 (Fig. 6a). While COL2A1 gene expression was significantly increased in the TGF- $\beta_{1}$-treated microaggregates ( $p<0.001$; Fig. 6a), only human NCCM-treated micro-aggregates contained some collagen type II protein (Fig. 6b). Furthermore, no significant differences were encountered for gene expression of $C C N D 1$ (proliferation marker), ADAMTS5 (extracellular matrix degradation), $C A S P 3$ (apoptosis marker), $B C L-2$ (anti-apoptosis marker) and $B A X$ (apoptosis marker) (data not shown). MMP13 (extracellular matrix degradation) gene expression was significantly upregulated in the TGF- $\beta_{1}-$, porcine-, and human NCCM-treated micro-aggregates compared with controls $(p<0.05)$, whereas collagen type 10 (COL10A1, marker of hypertrophy) gene expression was only detected in the TGF- $\beta_{1}$-treated micro-aggregates (data not shown). In contrast, collagen type $X$ protein was not detected in the micro-aggregates treated with TGF- $\beta_{1}$ or NCCM regardless of the donor species (Fig. 6b).

The GAG/DNA content of the micro-aggregates that were cultured in canine and porcine NCCM was significantly higher than those cultured in human NCCM $(p<0.001$; Fig. 7a). When the GAG/DNA content of the micro-aggregates was corrected for the DNA content (an indirect measure for cell number) of the NP tissue from which the NCCM was generated, porcine NCCM was more, and canine NCCM was less potent in increasing GAG deposition ( $p<0.01$, Fig. 7b). Also when the GAG/ DNA content of the micro-aggregates was corrected for the protein and GAG concentration of species-specific NCCM, porcine NCCM was significantly more potent than human and canine NCCM $(p<0.01$, Fig. $7 c$ and $7 d)$. 

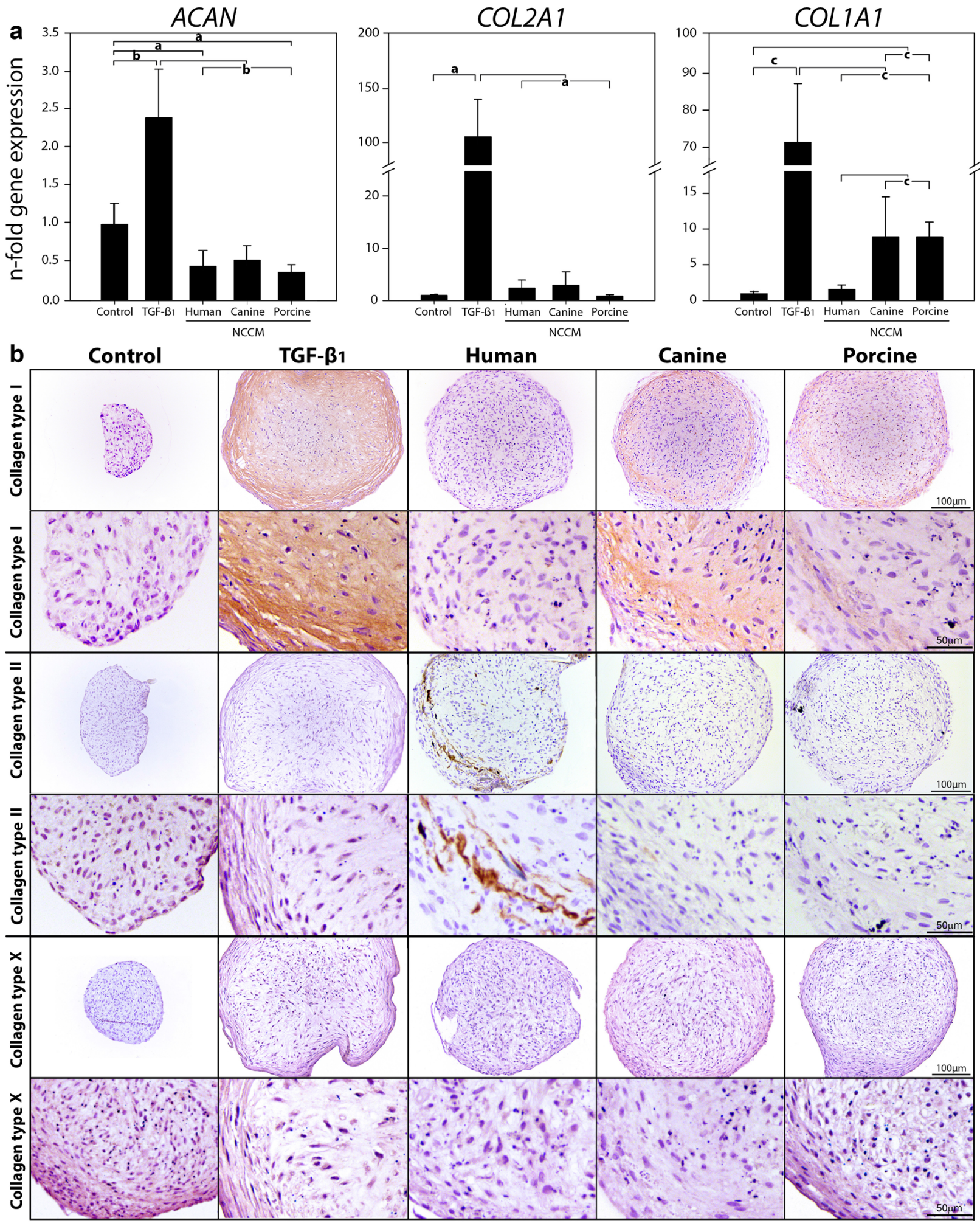

Fig. 6. Both canine and porcine NC-conditioned medium (NCCM) induces collagen type I production, whereas only human NCCM induces collagen type II production in human chondrocyte-like cells (CLCs) derived from degenerated intervertebral discs (IVDs). Extracellular matrix production of human CLCs derived from degenerated IVDs cultured in micro-aggregates in basal culture medium (control), chondrogenic culture medium (with $10 \mathrm{ng} / \mathrm{mL}$ TGF- $\beta_{1}$ ) and NCCM of different species. (a) Relative $A C A N$, COL2A1 and COL1A1 gene expression (mean \pm SD) of the micro-aggregates at day 7 . The control micro-aggregates were set at $1 . n=6$ per condition. a: $p<0.05$; b: $p<0.01$; c: $p<0.001$. (b) Immunohistochemical staining for collagen type I, II and X at day 28. Human: human NCCM (NX and HX samples pooled); Canine: canine NCCM (HX); Porcine: Porcine NCCM (HX). 

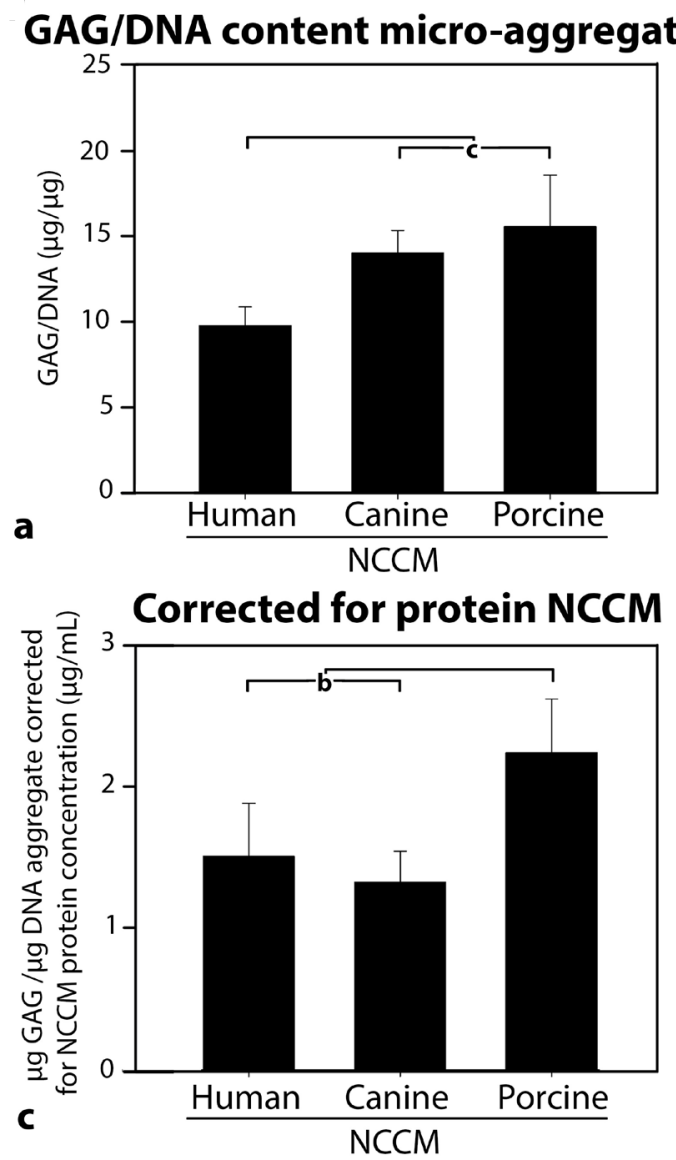
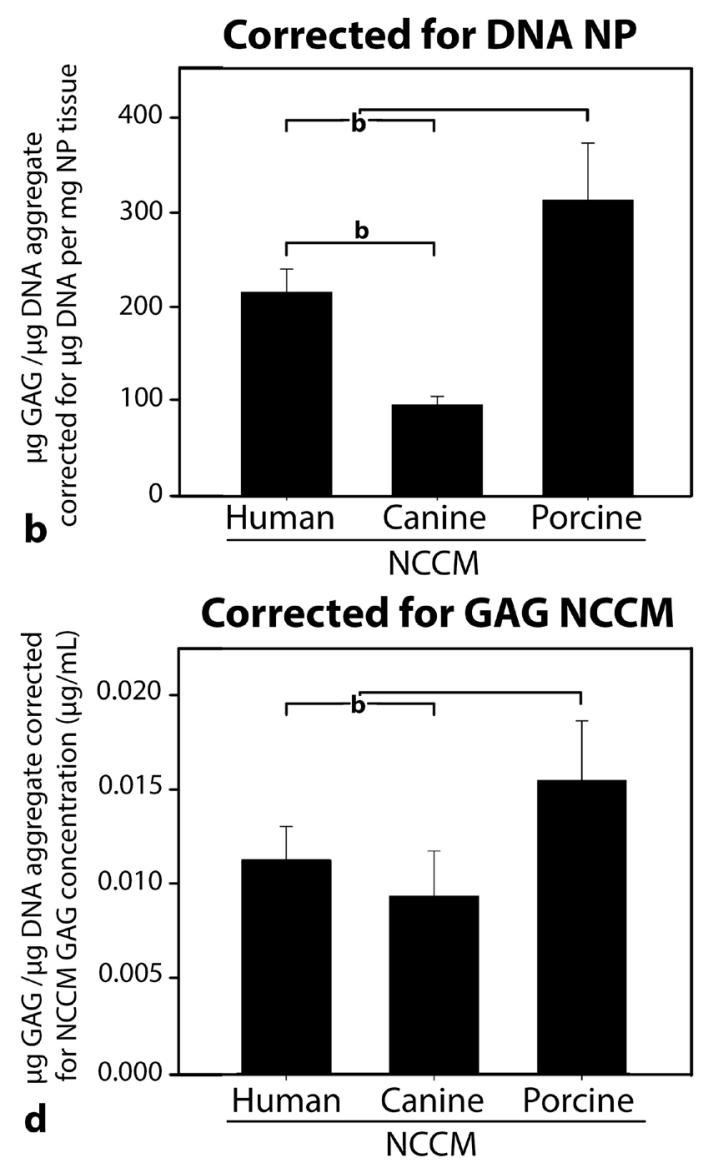

Fig. 7. The regenerative effect of porcine NC-conditioned medium (NCCM) is more potent than that of canine and human NCCM when corrected for nucleus pulposus (NP) or NCCM characteristics. GAG/DNA content of microaggregates derived from human CLCs derived from degenerated IVDs cultured in micro-aggregates in NCCM of different species for $28 \mathrm{~d}$. (a) GAG/DNA content (mean $\pm \mathrm{SD}$ ) of micro-aggregates cultured in species-specific NCCM. (b) Corrected for the DNA content of the NP tissue from which the NCCM was generated. (c) Corrected for the donors NCCM protein concentration. (d) Corrected for the donors NCCM GAG concentration. $n=8$ per condition. a: $p<0.05$; b: $p<0.01$; c: $p<0.001$; Human: human NCCM (NX and HX samples pooled); Canine: canine NCCM (HX); Porcine: Porcine NCCM (HX).

\section{Discussion}

Differential deposition of extracellular matrix by species-specific NCCM

Canine and porcine NC-secreted factors have already shown promising potential for IVD regeneration (Abbott et al., 2012; Gantenbein et al., 2014; Korecki et al., 2010; Mehrkens et al., 2013; Purmessur et al., 2011). The impact of human NC-secreted factors and the differential effects of xenogeneic NCCM on human CLCs, however, have never been investigated. The present study was, to our knowledge, the first to test the regenerative potential of human NCCM. Furthermore, this study sought to identify whether NC-secreted factors of different species exerted a differential regenerative effect on human CLCs derived from degenerated IVDs. This study demonstrates a crossspecies effect of bioactive NC-secreted factors on human CLCs derived from degenerated IVDs. NCCM of all species, generated under identical conditions on the basis of wet NP weight, increased CLC cell numbers and GAG deposition, but canine and porcine NCCM appeared more potent than human NCCM.

Although the IVD is an avascular hypoxic structure and several studies have demonstrated that NCs respond superior to hypoxic than normoxic culture conditions (Erwin et al., 2009; Omlor et al., 2014), no difference in regenerative potential was found between human NCCM generated under HX or NX conditions. Unpublished work by our group indicates that also no difference in biologic activity was established between canine NCCM that was generated under NX or HX conditions. In agreement with our studies, previous work demonstrating the regenerative potential of porcine and canine NC-secreted factors have used NCCM generated under HX (Abbott et al., 2012; Purmessur et al., 2011) and NX (Aguiar et al., 1999; Boyd et al., 2004; Erwin and Inman, 2006; Erwin et al., 2006; Erwin et al., 2011; Korecki et al., 2010) conditions. Altogether, this may imply that oxygen status during NCCM generation does not result in a differential biologic activity of NC-secreted factors on human CLCs. 
Matrix deposition by the degenerated CLCs could have been transcriptionally induced, but we cannot exclude the possibility that GAGs from the NCCM were incorporated in the deposited CLC matrix. Although increased GAG deposition was encountered in all NCCM-treated microaggregates and, albeit limited, collagen type II deposition was present in the human NCCM-treated micro-aggregates at day 28, gene expression of $A C A N$ and $C O L 2 A 1$ was not upregulated at day 7 . In line with our findings, expression of extracellular matrix-related genes is also not increased in porcine NCCM-treated cultures at day 2 (porcine CLCs) (Boyd et al., 2004), 7 (human CLCs) (Abbott et al., 2012) and 28 (bovine CLCs) (Potier et al., 2014). In contrast, an increased expression of extracellular matrix-related genes is encountered in canine NCCM-treated bovine CLCs after $1 \mathrm{~d}$ (Erwin et al., 2006) and canine CLCs after $28 \mathrm{~d}$ of treatment (de Vries et al., 2014). Human MSCs treated with porcine NCCM also demonstrate an increased expression of extracellular matrix-related genes at day 21 (Purmessur et al., 2011). In the above-mentioned studies, different cell types (CLC or MSC) and different species for cell culture/ NCCM generation were used. In addition, NCCM was generated in different ways (culture medium, additives, days of generation, whole NP tissue or NCs), and the cells were cultured using different systems and/or conditions, which hampers the comparison of results. Altogether, NCCM achieves regenerative effects by transcriptional regulation of anabolic matrix genes and we may have missed this time-window at $7 \mathrm{~d}$ of NCCM culture.

TGF- $\beta_{1}$ treatment induced undesirable fibrotic (re) differentiation of the CLCs, confirmed by a fibrotic rim around the micro-aggregates and increased collagen type I deposition, while even after $28 \mathrm{~d}$ of culture there was no evident collagen type II deposition. NCCM exerted a species-specific anabolic effect on human CLCs derived from degenerated IVDs. While porcine and canine NCCM were more potent in inducing GAG and collagen type I matrix deposition, only human NCCM induced collagen type II deposition. These differences imply that not only quantitative but also qualitative differences in bioactive factors may be present in human compared with canine or porcine NCCM. In addition, the bioactive substances in NCCM may be present in a suboptimal concentration. Therefore, future work should aim at the identification of GAG and collagen type II inducing factors in human, canine and porcine NCCM. Combinatory strategies with an optimal balance between bioactive NC-secreted factors may induce optimal NP matrix production. Moreover, the identified species-specific NC-secreted factors may also improve articular cartilage repair, in which GAG and collagen type II production is desirable.

\section{Species-specific NP properties may influence the observed regenerative capacity of NCCM}

In this study, phenotypical and biochemical differences between species of NP tissue and NCCM were established, which may account for the observed differential regenerative potency of species-specific NCCM. Numerous typical large, vacuolated NCs were encountered in all canine and porcine NPs (Hunter et al., 2003; Hunter et al., 2004; Smolders et al., 2013), but in very limited numbers in human NPs. Humans lose their NCs at about 6-10 years of age (Hunter et al., 2004), but in the present study, NCs were only scarcely present in foetal NPs. Only few cells with mainly a transitional or CLC phenotype were present in foetal human NP tissue, indicating that the NCs gradually obtained a mature phenotype (Purmessur et al., 2013b). Previous studies also reported mixed NC: CLC populations in foetal human NPs (Rutges et al., 2010; Shen et al., 2013). Specific conditions (e.g. hyperglycaemia) have been shown to cause premature NC apoptosis (Won et al., 2009). In the present study, human NC-rich NPs were obtained from non-viable individuals with specific disorders and/or anomalies, which may have influenced the health of the NP tissue and the presence of NCs within these NPs together with the gestation age of the donors. Inherently, the limited presence of NCs may have affected the regenerative potential of human NCCM in this study.

Overall, canine and porcine NCCM were equally potent and more potent than human NCCM in inducing CLC matrix production. However, when taking into account the cellularity (DNA content) of the NP tissue from which the NCCM was generated or the NCCM protein or NCCM GAG concentration, porcine NCCM appeared more potent than canine NCCM. The latter may have been influenced by the differences in lifespan and age (canine: 18-23 months, porcine: 3 months) of the donor species, which may translate into a differential regenerative effect related to NC-physiology. Hence, porcine NCCM may have exerted a relatively more potent regenerative effect than canine NCCM because of the young age of the porcine donors. Since all species have a different life span and lose their NCs at different ages, it would have been a challenge to find 'comparable' interspecies donors. Thus, it is impossible to distinguish species from aging effects of the NCCM. The ageing effect could be circumvented by employing healthy prenatal tissues at a species-specific developmental stage immediately after the development of the IVD. Nevertheless, from a practical point of view, canine and porcine NC-rich NP tissue is more easily available than human NC-rich NP tissue and both exerted a significant regenerative effect on human CLCs. Therefore, canine and in particular porcine donors are suitable for the development of NC-based technologies, in which the $\mathrm{NC}$-secreted bioactive factors can be identified, isolated and eventually synthesised in a human recombinant form.

\section{Limitations of the study}

The first limitation of this study is that passage 2 (P2) CLCs were used. Cell expansion for one or more passages likely induced dedifferentiation of the CLCs, a wellknown phenomenon for articular chondrocytes (Bekkers et al., 2014; Veilleux et al., 2004). Since dedifferentiated CLCs could respond differently from freshly isolated CLCs (P0), future studies should determine the effect of (species-specific) NCCM on P0 CLCs and explants. In order to overcome the sample volume limitations of the human NCCM (about $1 \mathrm{~mL}$ human NCCM was generated per donor), CLCs derived from IVDs with Thompson grade III from three human donors were pooled in order to assess a representative degenerated CLC population. For this reason, the regenerative effect of species-specific 
NCCM was also not tested on CLCs derived from human IVDs with other degeneration grades or on CLCs derived from other species. Furthermore, the human CLC microaggregates were cultured under normoxic conditions. CLCs may respond more pronounced to the bioactive NCsecreted factors under hypoxic than normoxic conditions given the hypoxic nature of the NP (Feng et al., 2013; Yang et al., 2013). Therefore, further research under hypoxic conditions is necessary to confirm the obtained results with CLCs from several donors with different IVD degeneration grades. Lastly, it remains to be elucidated if other (symptom modifying) markers were affected by NCCM treatment than the ones measured in the present study, e.g. anti-inflammatory/neurogenic/angiogenic markers (Purmessur et al., 2013a).

\section{Clinical relevance}

The present study showed that human, canine and porcine NC-secreted factors exerted regenerative effects on human CLCs isolated from degenerated IVDs. Future studies should concentrate on how NCs communicate with CLCs and which (species-specific) NC-secreted factors induce the regenerative effects. Once the bioactive NC-secreted factors have been identified and isolated, synthetic human recombinant products can be developed and their safety and efficacy can be determined. Since canine and porcine NC-secreted factors have a considerable regenerative potential and NC-rich NP tissue from these species is more easily available than human NC-rich NP tissue, canine or porcine NC-based regenerative treatments with synthetic human recombinant products have a promising potential for successful translation into humans.

\section{Conclusions}

This study demonstrated a cross-species effect of human, canine and porcine NC-secreted factors. NCCM derived from all these species exerted regenerative effects on human CLCs derived from degenerated IVDs in terms of GAG deposition and cell numbers. No difference in regenerative potential was found between human NCCM generated under hypoxic or normoxic conditions. The qualitative and quantitative differences in species-specific NP tissue and NCCM resulted in a differential regenerative effect on human CLCs. Given that canine and porcine NCrich NP tissue is more easily available than human NC-rich $\mathrm{NP}$ tissue and that both canine and porcine NC-secreted factors exerted regenerative effects on human CLCs, canine and in particular porcine donors are suitable to delineate the underlying bioactive substances resulting into IVD regeneration. Once the canine/porcine bioactive NCsecreted factors have been identified and isolated, synthetic human recombinant products can be developed and tested in vitro and in vivo. Combinatory strategies with an optimal balance between species-specific bioactive NC-secreted factors may further improve healthy NP matrix production.

\section{List of abbreviations}

AF: annulus fibrosus, CD: chondrodystrophic, CLC: chondrocyte-like cell, DMMB: dimethyl methylene blue, GAG: glycosaminoglycan, IHC: immunohistochemistry, IVD: intervertebral disc, HYP: hydroxyproline, HX: hypoxic, MSC: mesenchymal stromal cell, NC: notochordal cell, NCCM: NC conditioned medium, NCD: nonchondrodystrophic, NP: nucleus pulposus, NX: normoxic.

\section{Acknowledgements}

This work was funded by AOSpine International through an AO spine Research Network grant (SRN2011_11). Marianna Tryfonidou and Björn Meij were supported by the Dutch Arthritis Foundation (LLP22). The authors would like to thank Linda McPhee for professional scientific and language editing and Ferdi van Heel for assistance in cell culturing and analysis. The authors would like to thank Dr. P.G.J.Nikkels for providing foetal human IVD samples.

\section{Authors' contributions}

FB collected the material, performed all experiments, mined and analysed the data, participated in the design of the study, and drafted the manuscript. AK and LC collected the (foetal) human IVDs and supplied the CLCs. SdV collected porcine IVDs and generated porcine NCCM. $\mathrm{BM}$ and MT assisted in human NC-rich NP collection. FB, $\mathrm{BM}$, and MT collected and processed the canine IVDs. $\mathrm{KI}, \mathrm{BM}$ and MT conceived the study, helped to draft the manuscript and coordinated the process. All authors read and approved the final manuscript.

\section{Competing interests}

No competing financial interests associated with this publication exist that could have influenced this study's outcomes.

\section{References}

Abbott RD, Purmessur D, Monsey RD, Iatridis JC (2012) Regenerative potential of TGFbeta3 + Dex and notochordal cell conditioned media on degenerated human intervertebral disc cells. J Orthop Res 30: 482-488.

Aguiar DJ, Johnson SL, Oegema TR (1999) Notochordal cells interact with nucleus pulposus cells: regulation of proteoglycan synthesis. Exp Cell Res 246: 129-137.

Altschul SF, Madden TL, Schaffer AA, Zhang J, Zhang Z, Miller W, Lipman DJ (1997) Gapped BLAST and PSI-BLAST: a new generation of protein database search programs. Nucleic Acids Res 25: 3389-3402.

Bach FC, Willems N, Penning LC, Ito K, Meij BP, Tryfonidou MA (2014) Potential regenerative treatment strategies for intervertebral disc degeneration in dogs. BMC Vet Res 10: doi: 10.1186/1746-6148-10-3.

Bekkers JE, Saris DB, Tsuchida AI, van Rijen MH, Dhert WJ, Creemers LB (2014) Chondrogenic potential of articular chondrocytes depends on their original location. Tissue Eng Part A 20: 663-671. 
Bergknut N, Smolders LA, Grinwis GC, Hagman R, Lagerstedt AS, Hazewinkel HA, Tryfonidou MA, Meij BP (2013) Intervertebral disc degeneration in the dog. Part 1: Anatomy and physiology of the intervertebral disc and characteristics of intervertebral disc degeneration. Vet $\mathrm{J}$ 195: 282-291.

Boyd LM, Chen J, Kraus VB, Setton LA (2004) Conditioned medium differentially regulates matrix protein gene expression in cells of the intervertebral disc. Spine 29: 2217-2222.

Chujo T, An HS, Akeda K, Miyamoto K, Muehleman C, Attawia M, Andersson G, Masuda K (2006) Effects of growth differentiation factor-5 on the intervertebral discin vitro bovine study and in vivo rabbit disc degeneration model study. Spine 31: 2909-2917.

Colombini A, Lombardi G, Corsi MM, Banfi G (2008) Pathophysiology of the human intervertebral disc. Int J Biochem Cell Biol 40: 837-842.

Cornejo MC, Cho SK, Giannarelli C, Iatridis JC, Purmessur D (2015) Soluble factors from the notochordalrich intervertebral disc inhibit endothelial cell invasion and vessel formation in the presence and absence of pro-inflammatory cytokines. Osteoarthritis Cartilage 23: 487-496.

de Vries SA, Potier E, van Doeselaar M, Meij BP, Tryfonidou MA, Ito K (2014) Conditioned medium derived from notochordal cell-rich nucleus pulposus tissue stimulates matrix production by canine nucleus pulposus cells and bone marrow-derived stromal cells. Tissue Eng Part A 21: 1077-1084.

Erwin WM, Ashman K, O’Donnel P, Inman RD (2006) Nucleus pulposus notochord cells secrete connective tissue growth factor and up-regulate proteoglycan expression by intervertebral disc chondrocytes. Arthritis Rheum 54: 3859-3867.

Erwin WM, Inman RD (2006) Notochord cells regulate intervertebral disc chondrocyte proteoglycan production and cell proliferation. Spine 31: 1094-1099.

Erwin WM, Islam D, Inman RD, Fehlings MG, Tsui FW (2011) Notochordal cells protect nucleus pulposus cells from degradation and apoptosis: implications for the mechanisms of intervertebral disc degeneration. Arthritis Res Ther 13: R215.

Erwin WM, Las Heras F, Islam D, Fehlings MG, Inman RD (2009) The regenerative capacity of the notochordal cell: tissue constructs generated in vitro under hypoxic conditions. J Neurosurg Spine 10: 513-521.

Farndale RW, Sayers CA, Barrett AJ (1982) A direct spectrophotometric microassay for sulfated glycosaminoglycans in cartilage cultures. Connect Tissue Res 9: 247-248.

Feng G, Li L, Liu H, Song Y, Huang F, Tu C, Shen B, Gong Q, Li T, Liu L, Zeng J, Kong Q, Yi M, Gupte M, Ma PX, Pei F (2013) Hypoxia differentially regulates human nucleus pulposus and annulus fibrosus cell extracellular matrix production in 3D scaffolds. Osteoarthritis Cartilage 21: 582-588.

Gantenbein B, Calandriello E, Wuertz-Kozak K, Benneker LM, Keel MJ, Chan SC (2014) Activation of intervertebral disc cells by co-culture with notochordal cells, conditioned medium and hypoxia. BMC Musculoskelet Disord 15: 422-2474-15-422.

Gantenbein-Ritter B, Chan SC (2012) The evolutionary importance of cell ratio between notochordal and nucleus pulposus cells: an experimental 3-D co-culture study. Eur Spine J 21 Suppl 6: S819-25.

Gilbert HT, Hoyland JA, Richardson SM (2013) Stem cell regeneration of degenerated intervertebral discs: current status (update). Curr Pain Headache Rep 17: 377.

Henriksson H, Hagman M, Horn M, Lindahl A, Brisby $H$ (2011) Investigation of different cell types and gel carriers for cell-based intervertebral disc therapy, in vitro and in vivo studies. J Tissue Eng Regen Med 6: 738-747.

Hohaus C, Ganey TM, Minkus Y, Meisel HJ (2008) Cell transplantation in lumbar spine disc degeneration disease. Eur Spine J 17 Suppl 4: 492-503.

Huang KY, Yan JJ, Hsieh CC, Chang MS, Lin RM (2007) The in vivo biological effects of intradiscal recombinant human bone morphogenetic protein- 2 on the injured intervertebral disc: an animal experiment. Spine 32: 1174-1180.

Hunter CJ, Matyas JR, Duncan NA (2003) The notochordal cell in the nucleus pulposus: a review in the context of tissue engineering. Tissue Eng 9: 667-677.

Hunter CJ, Matyas JR, Duncan NA (2004) Cytomorphology of notochordal and chondrocytic cells from the nucleus pulposus: a species comparison. J Anat 205: 357-362.

Katz JN (2006) Lumbar disc disorders and low-back pain: socioeconomic factors and consequences. J Bone Joint Surg Am 88 Suppl 2: 21-24.

Korecki CL, Taboas JM, Tuan RS, Iatridis JC (2010) Notochordal cell conditioned medium stimulates mesenchymal stem cell differentiation toward a young nucleus pulposus phenotype. Stem Cell Res Ther 1: 18.

Kwon YJ, Lee JW, Moon EJ, Chung YG, Kim OS, Kim HJ (2013) Anabolic effects of Peniel 2000, a peptide that regulates TGF-beta1 signaling on intervertebral disc degeneration. Spine 38: E49-58.

Masuda K, Imai Y, Okuma M, Muehleman C, Nakagawa K, Akeda K, Thonar E, Andersson G, An HS (2006) Osteogenic protein-1 injection into a degenerated disc induces the restoration of disc height and structural changes in the rabbit anular puncture model. Spine 31: 742-754.

Mehrkens A, Karim MZ, Kim S, Hilario R, Fehlings MG, Erwin WM (2013) Canine notochordal cell-secreted factors protect murine and human nucleus pulposus cells from apoptosis by inhibition of activated caspase- 9 and caspase-3/7. Evid Based Spine Care J 4: 154-156.

Mochida J, Sakai D, Nakamura Y, Watanabe T, Yamamoto Y, Kato S (2015) Intervertebral disc repair with activated nucleus pulposus cell transplantation: a three-year, prospective clinical study of its safety. Eur Cell Mater 29: 202-212.

Mwale F, Masuda K, Pichika R, Epure LM, Yoshikawa T, Hemmad A, Roughley PJ, Antoniou J (2011) The efficacy of Link $\mathrm{N}$ as a mediator of repair in a rabbit model of intervertebral disc degeneration. Arthritis Res Ther 13: R120. 
Mwale F, Roughley P, Antoniou J (2004) Distinction between the extracellular matrix of the nucleus pulposus and hyaline cartilage: a requisite for tissue engineering of intervertebral disc. Eur Cell Mater 8: 58-64.

Neuman RE, Logan MA (1950) The determination of hydroxyproline. J Biol Chem 184: 299-306.

Omlor GW, Nerlich AG, Tirlapur UK, Urban JP, Guehring T (2014) Loss of notochordal cell phenotype in 3D-cell cultures: implications for disc physiology and disc repair. Arch Orthop Trauma Surg 134: 1673-1681.

Potier E, de Vries S, van Doeselaar M, Ito K (2014) Potential application of notochordal cells for intervertebral disc regeneration: an in vitro assessment. Eur Cell Mater 28: $68-81$.

Purmessur D, Schek RM, Abbott RD, Ballif BA, Godburn KE, Iatridis JC (2011) Notochordal conditioned media from tissue increases proteoglycan accumulation and promotes a healthy nucleus pulposus phenotype in human mesenchymal stem cells. Arthritis Res Ther 13: R81.

Purmessur D, Cornejo MC, Cho SK, Hecht AC, Iatridis JC (2013a) Notochordal cell-derived therapeutic strategies for discogenic back pain. Global Spine J 3: 201-218.

Purmessur D, Guterl CC, Cho SK, Cornejo MC, Lam YW, Ballif BA, Laudier JC, Iatridis JC (2013b) Dynamic pressurization induces transition of notochordal cells to a mature phenotype while retaining production of important patterning ligands from development. Arthritis Res Ther 15: R122.

Risbud MV, Schaer TP, Shapiro IM (2010) Toward an understanding of the role of notochordal cells in the adult intervertebral disc: from discord to accord. Dev Dyn 239: 2141-2148.

Rutges JP, Nikkels PG, Oner FC, Ottink KD, Verbout AJ, Castelein RJ, Creemers LB, Dhert WJ (2010) The presence of extracellular matrix degrading metalloproteinases during fetal development of the intervertebral disc. Eur Spine J 19: 1340-1346.

Saggese T, Redey P, McGlashan SR (2014) Samespecies phenotypic comparison of notochordal and mature nucleus pulposus cells. Eur Spine J 24: 1976-1985.

Shen J, Shi Q, Lu J, Wang DL, Zou TM, Yang HL, Zhu GQ (2013) Histological study of chordoma origin from fetal notochordal cell rests. Spine 38: 2165-2170.

Smolders LA, Bergknut N, Grinwis GC, Hagman R, Lagerstedt AS, Hazewinkel HA, Tryfonidou MA, Meij BP (2013) Intervertebral disc degeneration in the dog. Part 2: chondrodystrophic and non-chondrodystrophic breeds. Vet J 195: 292-299.

Veilleux NH, Yannas IV, Spector M (2004) Effect of passage number and collagen type on the proliferative, biosynthetic, and contractile activity of adult canine articular chondrocytes in type I and II collagen-glycosaminoglycan matrices in vitro. Tissue Eng 10: 119-127.

Won HY, Park JB, Park EY, Riew KD (2009) Effect of hyperglycemia on apoptosis of notochordal cells and intervertebral disc degeneration in diabetic rats. $\mathrm{J}$ Neurosurg Spine 11: 741-748.

Yang SH, Hu MH, Sun YH, Lin FH (2013) Differential phenotypic behaviors of human degenerative nucleus pulposus cells under normoxic and hypoxic conditions: influence of oxygen concentration during isolation, expansion, and cultivation. Spine J 13: 1590-1596.

Yim RL, Lee JT, Bow CH, Meij B, Leung V, Cheung KM, Vavken P, Samartzis D (2014) A systematic review of the safety and efficacy of mesenchymal stem cells for disc degeneration: insights and future directions for regenerative therapeutics. Stem Cells Dev 23: 2553-2567.

Zuker M (2003) Mfold web server for nucleic acid folding and hybridization prediction. Nucleic Acids Res 31: 3406-3415.

\section{Discussion with Reviewers}

Reviewer I: How do the authors propose to identify and isolate the secreted factors involved in the positive effects of NCCM?

Authors: To identify and isolate secreted factors involved in the regenerative effects of NCCM, it is important to know in which NCCM fraction the active components are located: the pelletable fraction (large protein aggregates or micro-vesicles/exosomes with cargo) or the soluble fraction (proteins). To determine this, these two fractions can be separated by ultracentrifugation and the (regenerative) effect of both fractions should be compared with complete NCCM in vitro. When the bioactive factors appear to be present in the soluble fraction, comparative proteomic analysis of the species-specific NCCM is proposed. When the bioactive factors appear to be present in the pelletable fraction, confocal microscopy can be used to determine the cellular uptake of vesicles and ultimately, proteomics, lipidomics, miRNA isolation and/or RNA sequencing are suitable techniques to determine the regenerative NCCM compounds.

Reviewer II: The authors found that human, canine and porcine NC-secreted factors exerted regenerative effects on human CLCs in micro-aggregate isolated from degenerated IVDs. Do the authors think that IVD cells obtained from trauma discs, thus healthy but short-term inflammatory dominated cells would response differently?

Authors: In the present study, NC-rich NP tissue from premature individuals was chosen as NCCM source, because it was hypothesised that NCs from this NP tissue would excrete most potent regenerative factors. It is, however, indeed very well possible that stressed NCs (e.g. by trauma) would excrete even more (potent) bioactive factors. However, trauma induces an immune response. Hence, generating NCCM from NC-rich NP tissue after acute herniation will be characterised in part by the synthesis of cytokines and chemokines and a coordinated infiltration of the herniated tissue. Inflammation can induce necrosis or apoptosis of cells, or even alteration of the typical NC phenotype, as described for stress induced by dynamic pressurisation (Purmessur et al., 2013b, text reference). However, a potentially beneficial role of the inflammatory process cannot be excluded, illustrating the dual nature of post-traumatic inflammation and the strong relationship between inflammation and regeneration. 
Reviewer II: Why was TGF $\beta_{1}(10 \mathrm{ng} / \mathrm{mL})$ as a positive control included rather than GDF5 (BMP14), it is clear that the response is a more chondrogenic/bone-inducing in the first and a more "discogenic" in the latter?

Authors: Indeed, the TGF- $\beta_{1}$ response is more chondrogenic/bone-inducing and the GDF5 response more discogenic, which would favour the use of GDF5. TGF- $\beta_{1}$ $(10 \mathrm{ng} / \mathrm{mL})$ was used as a positive control in the present study since it is widely used (in this concentration) in in vitro IVD studies as a positive control and the fact that this eases the comparison of inter-study results.

Reviewer III: Based on the multiple NC species and NC culture conditions applied in this study, it would be helpful for the authors to recommended best (or acceptable) species and culture conditions for future research on regenerative therapies.

Authors: The present study showed no difference in regenerative potential between human NCCM generated under hypoxic or normoxic conditions. However, it remains to be elucidated if other (symptom modifying) markers, e.g. anti-inflammatory/neurogenic/angiogenic markers, were also not affected by oxygen tension. In addition, in the present study, NCCM was generated in high glucose DMEM culture medium with 'standard' osmolarity (300 $\mathrm{mOsm} / \mathrm{L})$ in order to be able to compare these results to previous studies. However, we have shown previously that hyperosmolar (400 mOsm/L) aMEM had a beneficial effect on preserving the NC phenotype in culture (Spillekom et al., 2014, additional reference). Given that inflammation and regeneration are strongly related to each other, one could hypothesise that stressed/stimulated NCs (e.g. by suboptimal culture conditions) excrete even more (potent) bioactive factors in the NCCM resulting into more pronounced regenerative effects on human CLCs.

With regard to suitable donor species, the present study showed that human, canine and porcine NC-secreted factors exerted regenerative effects on human CLCs isolated from degenerated IVDs. The regenerative effect of porcine NCCM appeared more potent than that of canine and human NCCM, especially when corrected for NP or NCCM characteristics. Also from a practical point of view, canine and porcine NC-rich NP tissue is more easily available than human NC-rich NP tissue. Another (ethical) reason for using the porcine species is that spines are easily available at 3 months of age at slaughterhouses. Canine donors can also be suitable since they experience IVD disease in a similar manner as human patients, and treatment strategies can thus be translated to both veterinary and human patients with IVD disease. Therefore, canine and in particular porcine donors are recommended for future research on NC-based regenerative therapies. Notably, while porcine and canine NCCM were more potent in inducing GAG deposition by the CLCs, only human NCCM induced collagen type II deposition, indicating that quantitative as well as qualitative differences in bioactive factors may be present between species in NCCM. Therefore, future work should also determine the bioactive human NC-secreted factors. NC-based treatment strategies will profit from networks where comparative proteomic analysis of the NCCM from different species is related to the biologic response of the treated CLCs with special focus on matrix anabolism, anti-inflammatory and anti-neurogenic effects.

\section{Additional reference}

Spillekom S, Smolders LA, Grinwis GC, Arkesteijn IT, Ito K, Meij BP, Tryfonidou MA (2014) Increased osmolarity and cell clustering preserve canine notochordal cell phenotype in culture. Tissue Eng Part C Methods 20: 652-662.

Editor's Note: Scientific Editor in charge of the paper: Mauro Alini. 